\title{
Long term results of valve-sparing aortic root reconstruction
}

\author{
SJ Oh", KH Lee, HY Hwang, KH Kim, KB Kim, H Ahn \\ From 23rd World Congress of the World Society of Cardio-Thoracic Surgeons \\ Split, Croatia. 12-15 September 2013
}

\section{Background}

To present the early and late clinical outcomes of valvesparing aortic root reconstruction in patients with the various types of aortic root disease.

\section{Methods}

Between June 1996 and November 2012, 21 patients who underwent aortic valve sparing for aortic root aneurysm were retrospectively reviewed. Mean age was $45 \pm 16$ years. 9 patients had Marfan syndrome and one patient had Takayasu arteritis. All patients had tricuspid aortic valve except one patient with bicuspid valve, and 15 patients showed moderate or severe degree of aortic regurgitation. 15 patients were diagnosed with annuloaortic ectasia, 2 with ascending aortic aneurysm, 2 with aortic dissection and 2 with sinus valsalva aneurysm. Reimplantation of aortic root was performed in 13 patients and remodeling techniques in 8 . Mean follow up duration was 69.4 months.

\section{Results}

There were no operative mortality and one late-death. Survival of total patients at 5, 10, 15 years were 100, 83.3, $83.3 \%$, respectively. There was no major complication related to the operation. Moderate aortic regurgitation developed in 6 patients, but there was no severe aortic regurgitation. Any patient did not require reoperation during the follow up periods. Freedom from moderate or severe aortic regurgitation at 5 and 10 years were $82.5 \pm$ $9.3 \%$ and $70.7 \pm 13.5 \%$ for all patients, and there was no significant difference according to the type of operation. $(80.8 \pm 12.6 \%$, reimplantation vs. $71.4 \pm 17.1 \%$, remodeling, $\mathrm{p}=0.440)$.

\footnotetext{
* Correspondence: wpwnn@hanmail.net

* Correspondence: wpwnn@hanmail.net
Department of Thoracic and Cardiovascular Surgery, SMG-SNU Boramae Medical Center, Seoul, Korea
}

(c) 2013 Oh et al; licensee BioMed Central Ltd. This is an Open Access article distributed under the terms of the Creative Commons

\section{Conclusions}

Aortic valve-sparing aortic root reconstruction including both implantation and remodeling technique provides the good clinical outcomes and is associated with low rates of valve related complications.

Published: 11 September 2013

doi:10.1186/1749-8090-8-S1-049

Cite this article as: Oh et al: Long term results of valve-sparing aortic root reconstruction. Journal of Cardiothoracic Surgery 2013 8(Suppl 1):O49. and take full advantage of:

- Convenient online submission

- Thorough peer review

- No space constraints or color figure charges

- Immediate publication on acceptance

- Inclusion in PubMed, CAS, Scopus and Google Scholar

- Research which is freely available for redistribution 